\title{
Familial Mediterranean fever: What associations to screen for?
}

\author{
Salem Bouomrani, Ines Masmoudi, Sawssan Ben Teber
}

Sfax Faculty of Medicine, University of Sfax, Tunisia

Department of Internal Medicine, Military Hospital of Gabes, Tunisia

\begin{abstract}
Familial Mediterranean fever (FMF) is the most common and best known of hereditary recurrent fever or periodic fever syndromes. It was described in 1945 and genetically characterized in 1992. It is caused by a point mutation in the MEFV gene located on the short arm of chromosome 16. It is particularly frequent among Sephardic Jews, Armenians, Turks and Middle Eastern Arabs, where the prevalence can reach $1 / 2000$ to $1 / 1000$.

Recent publications described its frequent association with other diseases and/or syndromes, particularly those of autoimmune, genetic, and autoinflammatory origin.

The objective of this review is to familiarize healthcare professionals with the main associations to look for in patients followed for FMF. The early detection of these associations makes it possible to improve the management and the prognosis of patients with FMF.
\end{abstract}

Key words: familial Mediterranean fever, periodic fever, pyrin, chronic inflammation, MEFV gene.

\section{Introduction}

Familial Mediterranean fever (FMF) is an autoinflammatory disease with genetic transmission described in 1945 [1] and its characteristic mutation identified in 1992 [2, 3]. It is particularly frequent among Sephardic Jews, Armenians, Turks and Middle Eastern Arabs, where the prevalence can reach $1 / 2000$ among Jews and $1 / 1000$ for Turks and Armenians [1, 4].

It is caused by a point mutation in the MEFV gene located on the short arm of chromosome $16[1,4,5]$. This mutation leads to the production of a mutant protein pyrin and thus causes disruption of the normal inflammatory response and cellular apoptosis [4, 5].

Clinically, FMF is characterized by painful paroxys mal and febrile peritoneal, pleural, and joint attacks, which can be associated with various systemic manifestations: cutaneous, neurological, cardiac, urogenital and hematopoietic [1-4].

Several diagnostic criteria, the most used of which are those of Livneh [6], help in the positive diagnosis of this disease, but the confirmation is genetic, based on the demonstration of mutations in the MEFV gene, of which there are more than twenty. The most frequent of these mutations are M694V, M694I, V726A, and E148Q [4, 7].

Recent publications have described its frequent association with other diseases and/or syndromes, the common denominators of which are genetic predisposition, immune dysfunction, and auto-inflammation. It is therefore important for health professionals to know these associations in order to detect them in time and initiate appropriate care without delay. This approach is the only guarantee to improve the prognosis of this disease, often reserved.

\section{Familial Mediterranean fever and its most frequent associations}

Several associations have been described with FMF; the most frequent are spondyloarthropathies, systemic vasculitis, and inflammatory bowel disease (IBD).

\section{Familial Mediterranean fever and spondyloarthropathies}

A significant association between FMF and spondyloarthropathies in general and ankylosing spondylitis in 
particular has been reported by several authors [8-11]. In fact, $7.5 \%$ of subjects with FMF in the Akar et al. [9] series had associated ankylosing spondylitis. The relative risk (RR) of having spondyloarthropathy and specifically ankylosing spondylitis was also very high in the first degree parents of a subject with FMF compared to the general population ( $\mathrm{PR}=3.3$ and 2.9 respectively) [11].

This association is reinforced by the particular frequency of enthesopathies in subjects with FMF [12] suggesting that the mutant MEFV gene could partially promote such an association [11, 13].

In addition, a statistically significant association has been demonstrated between mutations in the MEFV gene, in particular that of type M694V, and ankylosing spondylitis (even without known FMF): $10.7 \%$ vs. only $4.2 \%$ in the general population, $p=0.06$ in the series of Yigit et al. [10] and 22.3\% vs. only 9.7\% for all "nonsense" mutations of the MEFV gene in the Cosan et al. series [14].

\section{Familial Mediterranean fever and systemic vasculitis}

The most frequent association is with Henoch-Schönlein syndrome or purpura (HSS) [15, 16]. In fact, in the series of 68 patients with HSS of Altug et al. [17], 26\% had an associated FMF. This particularly frequent association between HSS and FMF strongly suggests that MEFV could be the causative gene for HSS, the etiopathogenesis of which has not yet been elucidated [18]: in the series of 72 children with HSS of Dogan et al. [19], 11 (14.4\%) had the MEFV gene mutation in its heterozygous form, 5 (6.6\%) in its homozygous form, and 2 (2.6\%) in its heterozygous composite form. In addition, seven of these patients presented at the same time two distinct mutations of the MEFV gene, which was clearly significant compared to the general population (9.2\% vs. 1\%) [19].

Other systemic vasculitides are also reported to be associated with FMF: panarteritis nodosa, protracted febrile myalgia syndrome (PFMS syndrome), Behçet's disease [11, 17, 20-22], and Takayasu arteritis [23, 24].

To approach the mechanism of these associations, the study by Aytekin et al. [22] seems very interesting by revealing a particularly high frequency of vascular anomalies on capillaroscopy during FMF (capillary enlargement and microhemorrhages). These anomalies which characterize systemic vasculitides suggest systemic angiitis of the small vessels as a mediator of FMF clinical symptoms [22]. This hypothesis is reinforced by the original observation of Girisgen et al. [16] reporting the concomitant association of FMF with two systemic vasculitides (HSS and panarteritis nodosa).

In summary, among the systemic vasculitides associated with FMF, HSS and classic panarteritis nodo- sa are the most frequent $[11,24]$; next come the PFMS syndrome and Behçet's disease [11]. The other systemic vasculitides are more exceptional [23, 24].

\section{Familial Mediterranean fever and inflammatory bowel disease}

Inflammatory bowel disease (Crohn's disease and ulcerative colitis) are far from rare during FMF [11, 25-28]. In fact, 22 (15.4\%) in the series of 78 patients suffering from FMF of Beser OF et al. [26] had concomitant endoscopically and histologically confirmed IBD. Likewise, the presence of the MEFV gene mutation was significantly more often found in patients with histologically confirmed IBD: $28 \%$ in ulcerative colitis, and $22.6 \%$ in Crohn's disease vs. only $9.9 \%$ in the healthy controls; $p=$ $0.006[27]$.

\section{Familial Mediterranean fever and multiple sclerosis}

This association reported by several authors [11, 29-32] but too long controversial [33] has just been recently proven by the large national study of Yahalom et al. (one of the largest series of FMF) where the frequency of multiple sclerosis in patients with FMF was $0.075 \%=$ three times that of the general population ( $p=0.0057$ ); in addition, the presence of the M694V mutation worsened the clinical picture of multiple sclerosis in these patients [34].

On the other hand, the study of Unal et al. [29] had shown a significant frequency of the mutation of the MEFV gene in patients with multiple sclerosis compared to the general population: $38 \%$ vs. only $11 \%, p<0.0001$.

These findings suggest the mutation of the MEFV gene as a potential predisposing factor for multiple sclerosis, in particular the E148Q type mutation [32].

\section{Familial Mediterranean fever and rheumatoid arthritis}

This association is increasingly reported in the world literature [35-39], and a significantly higher frequency of anti-citrullinated protein antibodies (ACPA) (specific for rheumatoid arthritis) has been found in patients with FMF: $14.5 \%$ vs. only $4.7 \%$ in the general population (3 times higher); their presence was significantly associated with arthritis during FMF [40].

\section{Familial Mediterranean fever and juvenile idiopathic arthritis}

This association is also far from rare. It has been reported by several authors [41-43]. It has been shown that the frequency of the specific M694V mutation of the MEFV gene during JIA is around $10 \%$, and its pres- 
Table I. Main clinical associations of familial Mediterranean fever presented in the literature

\begin{tabular}{|ll|}
\hline Most frequent associations & Rarer associations \\
\hline Spondyloarthropathies, specifically ankylosing spondylitis & Systemic lupus erythematosus \\
\hline $\begin{array}{l}\text { Systemic vasculitis: Henoch-Schönlein syndrome, panarteritis } \\
\text { nodosa, protracted febrile myalgia syndrome (PFMS syndrome), } \\
\text { Behçet's disease, Takayasu arteritis }\end{array}$ & Sarcoidosis and Blau syndrome \\
\hline Inflammatory bowel disease: Crohn's disease and ulcerative colitis & Kartagener syndrome \\
\hline Multiple sclerosis & Gitelman syndrome \\
\hline Rheumatoid arthritis and juvenile idiopathic arthritis & Fabry syndrome \\
\hline Non-alcoholic fatty liver disease & Celiac disease \\
\hline & Polymyositis and juvenile dermatomyositis \\
\hline & Beta-thalassemia \\
\hline & Atrophic polychondritis \\
\hline & Fibromyalgia \\
\hline & Eosinophilic gastroenteritis \\
\hline & Tumor necrosis factor receptor-1 syndrome \\
(TRAPS syndrome)
\end{tabular}

ence makes juvenile idiopathic arthritis (JIA) more severe and more resistant to the usual treatment requiring the use of biotherapy [41]. Also the presence of all types of MEFV mutations was significantly higher in JIA compared to the general population: $14.28 \%$ vs. only $5 \%$, $p<0.01 \%$ [41].

Therefore, it is recommended to screen for MEFV gene mutations in children presumed to have JIA, especially those of male gender, in the case of enthesopathies and negative anti-nuclear antibodies [44].

\section{Familial Mediterranean fever and non-alcoholic fatty liver disease}

In the series of Rimar et al. [45], 74\% of patients with FMF presented non-alcoholic fatty liver disease (NAFLD) ranging from simple hepatic steatosis (5/21 patients) to non-alcoholic steatohepatitis (NASH): $3 / 21$ patients, and cirrhosis on NASH: 7/21 patients, and this apart from any underlying metabolic syndrome, suggesting a strong association between FMF and NAFLD.

\section{Familial Mediterranean fever and its rarer associations}

Other rarer associations have been reported, with: systemic lupus erythematosus [46-48], sarcoidosis [38], Blau syndrome [49], Kartagener syndrome [50], Gitelman syndrome [51], Fabry syndrome [52], celiac disease [53], polymyositis [54], juvenile dermatomyositis [55], beta-thalassemia [56], atrophic polychondritis [57], fibromyalgia [58], eosinophilic gastroenteritis [59], and tumor necrosis factor receptor-1 syndrome (TRAPS syndrome) [60].
Table I summarizes the main associations found in the literature with FMF.

\section{Conclusions}

Knowledge of these associations, especially the most common, is very useful for healthcare professionals caring for patients with FMF. Their diagnosis is not always easy since many of these diseases can cause the same symptoms or have similar clinical presentations.

The early detection of these associations makes it possible to improve the management and the prognosis of patients with FMF.

The authors declare no conflict of interest.

\section{References}

1. Etem E, Deveci SD, Erol D, et al. Familial Mediterranean Fever: a retrospective clinical and molecular study in the East of Anatolia region of Turkey. Open Rheum J 2010; 4: 1-6, DOI: 10.2174/1874312901004010001.

2. The French FMF consortium. A candidate gene for familiar Mediterranean fever. Nat Genet 1997; 17: 25-31.

3. International FMF Consortium: Ancient missense mutations in a new member of the RoRet gene family are likely to cause familial Mediterranean fever. Cell 1997; 90: 797-807, DOI: 10.1016/s0092-8674(00)80539-5.

4. Medlej-Hashim M, Loiselet J, Lefranc G, Mégarbané A. Familial Mediterranean Fever (FMF): from diagnosis to treatment. Sante 2004; 14: 261-266.

5. Tidow N, Chen X, Müller C, et al. Hematopoietic-specific expression of MEFV, the gene mutated in familial Mediterranean fever, and subcellular localization of its corresponding protein, pyrin. Blood 2000; 95: 1451-1455. 
6. Livneh A, Lagevitz P, Zemer D, et al. Criteria for the diagnosis of familial Mediterranean fever. Arthritis Rheum 1997; 40: 1879 1885, DOI: 10.1002/art.1780401023.

7. Touitou I. The spectrum of Familial Mediterranean Fever (FMF) mutations. Eur J Hum Genet 2001; 9: 473-483, DOI: 10.1038/ sj.ejhg. 5200658.

8. Estublier C, Stankovic Stojanovic K, Bergerot JF, et al. Myositis in a patient with familial Mediterranean fever and spondyloarthritis successfully treated with anakinra. Joint Bone Spine 2013; 80: 645-649, DOI: 10.1016/j.jbspin.2013.03.004.

9. Akar S, Soysal O, Balci A, et al. High prevalence of spondyloarthritis and ankylosing spondylitis among familial Mediterranean fever patients and their first-degree relatives: further evidence for the connection. Arthritis Res Ther 2013; 15: R21, DOI: $10.1186 /$ ar4154.

10. Yigit S, Inanir A, Karakus N, et al. Common Mediterranean fever (MEFV) gene mutations associated with ankylosing spondylitis in Turkish population. Dis Markers 2012; 33: 113-118, DOI: 10.1155/2012/890214.

11. Aksu K, Keser G. Coexistence of vasculitides with familial Mediterranean fever. Rheumatol Int 2011; 31: 1263-1274, DOI: 10.1007/s00296-011-1840-z.

12. Ozkan F, Cetin GY, Inci MF, et al. Increased enthesopathy in patients with familial Mediterranean fever: evaluation with a new sonographic enthesitis index. J Ultrasound Med 2013; 32: 325-332, DOI: 10.7863/jum.2013.32.2.325.

13. Tufan A, Mercan R, Tezcan ME, et al. Enthesopathy in patients with familial Mediterranean fever: increased prevalence in M694 V variant. Rheumatol Int 2013; 33: 1933-1937, DOI: 10.1007/s00296-013-2669-4.

14. Cosan F, Ustek D, Oku B, et al. Association of familial Mediterranean fever-related MEFV variations with ankylosing spondylitis. Arthritis Rheum 2010; 62: 3232-3236, DOI: 10.1002/ art. 27683.

15. Cabral M, Conde M, Brito MJ, et al. Protracted Febrile Myalgia Syndrome with Henoch-Schönlein Purpura: an atypical presentation of Familial Mediterranean Fever. Acta Reumatol Port 2011;36: 69-74.

16. Girisgen I, Sonmez F, Koseoglu K, et al. Polyarteritis nodosa and Henoch-Schönlein purpura nephritis in a child with familial Mediterranean fever: a case report. Rheumatol Int 2012; 32: 529-533, DOI: 10.1007/s00296-010-1766-X.

17. Altug U, Ensari C, Sayin DB, Ensari A. MEFV gene mutations in Henoch-Schönlein purpura. Int J Rheum Dis 2013; 16: $347-$ 351, DOI: 10.1111/1756-185X.12072.

18. He X, Yu C, Zhao P, et al. The genetics of Henoch-Schönlein purpura: a systematic review and meta-analysis. Rheumatol Int 2013; 33: 1387-1395, DOI: 10.1007/s00296-012-2661-4.

19.Dogan CS, Akman S, Koyun M, et al. Prevalence and significance of the MEFV gene mutations in childhood Henoch-Schönlein purpura without FMF symptoms. Rheumatol Int 2013; 33: 377-380, DOI: 10.1007/s00296-012-2400-x.

20. Luger S, Harter PN, Mittelbronn M, et al. Brain stem infarction associated with familial Mediterranean fever and central nervous system vasculitis. Clin Exp Rheumatol 2013;31 (3 Suppl 77): 93-95.
21. Ozçakar ZB, Yalçınkaya F. Vascular comorbidities in familial Mediterranean fever. Rheumatol Int 2011; 3: 1275-1281, DOI: 10.1007/s00296-011-1845-7.

22. Aytekin S, Aydin F, Akpolat T, et al. Evaluation of nailfold capillaries in familial Mediterranean fever patients. Clin Rheumatol 2011; 30: 255-257, DOI: 10.1007/s10067-010-1609-x.

23. Alibaz-Oner F, Yilmaz N, Can M, Direskeneli H. A case of Takayasu's arteritis associated with familial Mediterranean fever. Clin Exp Rheumatol 2012; 30 (3 Suppl 72): S117.

24.Zihni FY, Kalfa M, Ocakçı PT, et al. Coexistence of Takayasu's arteritis with familial Mediterranean fever. Rheumatol Int 2012; 32: 1675-1678, DOI: 10.1007/s00296-011-1853-7.

25. Kuloğlu Z, Kansu A, Ustündağ G, et al. An infant with severe refractory Crohn's disease and homozygous MEFV mutation who dramatically responded to colchicine. Rheumatol Int 2012; 32: 783-785, DOI: 10.1007/s00296-009-1326-4.

26. Beşer OF, Kasapçopur O, Cokuğraş FC, et al. Association of inflammatory bowel disease with familial Mediterranean fever in Turkish children. J Pediatr Gastroenterol Nutr 2013; 56: 498502, DOI: 10.1097/MPG.0b013e31827dd763.

27. Akyuz F, Besisik F, Ustek D, et al. Association of the MEFV gene variations with inflammatory bowel disease in Turkey. J Clin Gastroenterol 2013; 47: e23-27, DOI: 10.1097/ MCG.0b013e3182597992.

28. Uslu N, Demir H, Balta G, et al. Hemophagocytic syndrome in a child with severe Crohn's disease and familial Mediterranean fever. J Crohns Colitis 2010; 4: 341-344, DOI: 10.1016/j. crohns.2009.12.005.

29. Unal A, Dursun A, Emre U, et al. Evaluation of common mutations in the Mediterranean fever gene in Multiple Sclerosis patients: Is it a susceptibility gene? J Neurol Sci 2010; 294: 38-42, DOI: 10.1016/j.jns.2010.04.008.

30. Unal A, Emre U, Dursun A, Aydemir S. The co-incidence of multiple sclerosis in a patient with familial Mediterranean fever. Neurol India 2009; 57: 672-673, DOI: 10.4103/00283886.57790 .

31. Alpayci M, Bozan N, Erdem S, et al. The possible underlying pathophysiological mechanisms for development of multiple sclerosis in familial Mediterranean fever. Med Hypotheses 2012; 78: 717-720, DOI: 10.1016/j.mehy.2012.02.017.

32. Kümpfel T, Gerdes LA, Wacker T, et al. Familial Mediterranean fever-associated mutation pyrin E148Q as a potential risk factor for multiple sclerosis. Mult Scler 2012; 18: 1229-1238, DOI: 10.1177/1352458512437813.

33. Yahalom G, Kivity S, Lidar M, et al. Familial Mediterranean fever (FMF) and multiple sclerosis: an association study in one of the world's largest FMF cohorts. Eur J Neurol 2011; 18: 11461150, DOI: 10.1111/j.1468-1331.2011.03356.x.

34.Bouomrani S, Guermazi M. Multiple Sclerosis and Familial Mediterranean Fever: Myth or Reality? Ann Mult Scler Res 2019; 1: 1003.

35. Mori S, Yonemura K, Migita K. Familial Mediterranean fever occurring in an elderly Japanese woman with recent-onset rheumatoid arthritis. Intern Med 2013; 52: 385-388, DOI: 10.2169/ internalmedicine.52.9102.

36. Koca SS, Etem EO, Isik B, et al. Prevalence and significance of MEFV gene mutations in a cohort of patients with rheumatoid 
arthritis. Joint Bone Spine 2010; 77: 32-35, DOI: 10.1016/j.jbspin.2009.08.006.

37. Migita K, Abiru S, Sasaki O, et al. Coexistence of familial Mediterranean fever and rheumatoid arthritis. Mod Rheumatol 2014; 24: 212-216, DOI: 10.3109/14397595.2013.852843.

38. Erten S, Erzurum C, Kosker TA, et al. Two cases of familial Mediterranean fever associated with sarcoidosis (Lofgren's syndrome) and rheumatoid arthritis. Int J Rheum Dis 2013; 16: 373-375, DOI: 10.1111/1756-185X.12004.

39. Migita K, Abiru S, Sasaki O, et al. Coexistence of familial Mediterranean fever and rheumatoid arthritis. Mod Rheumatol 2014; 24: 212-216, DOI: 10.3109/14397595.2013.852843.

40. Ceri M, Unverdi S, Altay M, et al. Anti-cyclic citrullinated peptides positivity rate in patients with familial Mediterranean fever. Clin Exp Rheumatol 2010; 28 (4 Suppl 60): S58-61.

41. Ayaz NA, Ozen S, Bilginer Y, et al. MEFV mutations in systemic onset juvenile idiopathic arthritis. Rheumatology (Oxford) 2009; 48: 23-25, DOI: 10.1093/rheumatology/ken409.

42. Kaya S, Kaptanoglu E, Elden H, Hizmetli S. Coexistence of familial Mediterranean fever and juvenile idiopathic arthritis with osteoporosis successfully treated with etanercept. Intern Med 2010; 49: 619-622, DOI: 10.2169/internalmedicine.49.2777 .

43. Cantarini L, Lucherini OM, Simonini G, et al. Systemic-onset juvenile idiopathic arthritis complicated by early onset amyloidosis in a patient carrying a mutation in the MEFV gene. Rheumatol Int 2012; 32: 465-467, DOI: 10.1007/s00296-0091331-7.

44. Comak E, Dogan CS, Akman S, et al. MEFV gene mutations in Turkish children with juvenile idiopathic arthritis. Eur J Pediatr 2013; 172: 1061-1067, DOI: 10.1007/s00431-013-2003-x.

45. Rimar D, Rosner I, Rozenbaum M, Zuckerman E. Familial Mediterranean fever: an association with non-alcoholic fatty liver disease. Clin Rheumatol 2011; 30: 987-991, DOI: 10.1007/ s10067-011-1718-1.

46. Inamo $\mathrm{Y}$, Hayashi R, Saito $\mathrm{K}$, et al. A Japanese pediatric patient with coexisting systemic lupus erythematosus and $\mathrm{fa}$ milial Mediterranean fever. Lupus 2013; 22: 1056-1059, DOI: 10.1177/0961203313497117.

47. Matsuda M, Kishida D, Tsuchiya-Suzuki A, et al. Periodic peritonitis due to familial Mediterranean fever in a patient with systemic lupus erythematosus. Intern Med 2010; 49: 22592262, DOI: 10.2169/internalmedicine.49.4043.

48. Yildiz G, Kayatas M, Uygun Y, et al. Coexistence of systemic lupus erythematosus and familial Mediterranean fever. Intern Med 2010; 49: 767-769, DOI: 10.2169/internalmedicine.49.3102.
49. Oğuz ID, Gönül M, Çakmak SK, et al. A case of Beau's lines associated with familial Mediterranean fever. Int J Dermatol 2014; 53: e121-2, DOI: 10.1111/j.1365-4632.2012.05618.x.

50. Cetin D, Genç Çetin B, Sentürk T, et al. Coexistence of two rare genetic disorders: Kartagener syndrome and familial Mediterranean fever. Mod Rheumatol 2015; 25: 312-314, DOI: 10.3109/14397595.2013.874756

51. Erten S, Ceylan GG, Altunoğlu A. Concomitance of Gitelman syndrome and familial Mediterranean fever: A rare case presentation. Ren Fail 2012; 34: 1333-1334, DOI: 10.3109/0886022X.2012.718950

52.Zizzo C, Colomba P, Albeggiani G, et al. Misdiagnosis of familial Mediterranean fever in patients with Anderson-Fabry disease. Clin Genet 2013; 83: 576-581, DOI: 10.1111/j.13990004.2012.01940.x.

53. Krums LM, Golovanova EV, Khomeriki SG, et al. Celiac disease is a 33-year-old man with periodic disease. Eksp Klin Gastroenterol 2012; 3: 114-117.

54. Eguchi M, Miyashita T, Shirouzu H, et al. Coexistence of polymyositis and familial Mediterranean fever. Mod Rheumatol 2013; 23: 374-378, DOI: 10.1007/s10165-012-0649-2.

55. Bouomrani S, Mesfar R, Ben Ayed M, et al. Juvenile dermatomyositis associated to Familial Mediterranean Fever. Am J Med Case Rep 2019; 7:170-172, DOI: 10.12691/ajmer-7-8-5.

56. Aslan D. Familial Mediterranean fever with a single MEFV mutation: can a deletion resulting in $\alpha$-thalassemia be the cause? J Hum Genet 2011; 56: 169-171, DOI: 10.1038/jhg.2010.160.

57. Miller EB, Friedman JA, Lahav Y, Landau Z. Relapsing polychondritis and familial Mediterranean fever - an association. Clin Rheumatol 2011; 30: 711-713, DOI: 10.1007/s10067-0101673-2.

58. Feng J, Zhang Z, Li W, et al. Missense mutations in the MEFV gene are associated with fibromyalgia syndrome and correlate with elevated IL-1 beta plasma levels. PLoS One 2009; 4: e8480, DOI: 10.1371/journal.pone.0008480.

59. Kocak G, Kocak E, Yilmaz SR, et al. MEFV gene mutations in a patient with eosinophilic gastroenteritis. South Med J 2010; 103: 1170-1172, DOI: 10.1097/SMJ.0b013e3181f468b4.

60. Clementi A, Cruz ND, Granata A, et al. Secondary amyloidosis in a patient carrying mutations in the familial Mediterranean fever (FMF) and tumour necrosis factor receptor-1 syndrome (TRAPS) genes. Clin Kidney J 2013; 6: 613-617, DOI: 10.1093/ ckj/sft112.w 